\title{
Short-term Treatment of Gastroesophageal Reflux Disease
}

\section{A Systematic Review and Meta-analysis of the Effect of Acid-suppressant Drugs in Empirical Treatment and in Endoscopy-negative Patients}

Bart van Pinxteren, MD, Mattijs E. Numans, MD, PhD, Joseph Lau, MD, Niek J. de Wit, MD, PhD, A. Pali S. Hungin, MBBS, MD, FRCGP, Peter A. L. Bonis, MD

OBJECTIVE: To investigate the efficacy of acid suppressant drugs in the empirical treatment of gastroesophageal reflux disease (GERD) and in the treatment of endoscopy-negative reflux disease (ENRD).

DESIGN: MEDLINE, EMBASE, and the Cochrane Controlled Trials Register were searched. Bibliographies were reviewed.

SETTING: Studies were eligible that compared the short-term use of proton pump inhibitors (PPIs) and histamine-2 receptor antagonists $\left(\mathrm{H}_{2} \mathrm{RAs}\right)$ with each other or with placebo in adults with GERD who were enrolled irrespective of endoscopic findings (empirical cases) or in whom endoscopy showed no signs of esophagitis (endoscopy-negative cases).

MEASUREMENTS: Of 1,408 studies, only 13 could be included for meta-analysis. Data on 3,433 patients empirically treated for GERD and 2,520 patients treated for ENRD were extracted. The primary endpoint was relief of heartburn.

MAIN RESULTS: In the empirical treatment of GERD, the summary relative risk (sRR) for symptom relief from $\mathrm{H}_{2} \mathrm{RAs}$ versus placebo was 0.77 (95\% confidence interval [95\% CI], 0.60 to 0.99 ). RR in the only placebo-controlled PPI trial was 0.35 (95\% CI, 0.26 to 0.46). The sRR for standard dose PPIs versus $\mathrm{H}_{2}$ RAs was 0.55 ( $95 \% \mathrm{CI}, 0.44$ to 0.68 ). In treatment of ENRD, both PPIs (sRR, 0.64; 95\% CI, 0.52 to 0.79 ) and $\mathrm{H}_{2} R A s$ (sRR, $0.78 ; 95 \% \mathrm{CI}, 0.62$ to 0.97 ) were superior to placebo, and PPIs were superior to $\mathrm{H}_{2} \mathrm{RAs}$ (sRR, $0.81 ; 95 \% \mathrm{CI}, 0.70$ to 0.95).

CONCLUSIONS: Acid suppressant therapy (with a PPI or an $\mathrm{H}_{2} \mathrm{RA}$ ) is more effective than placebo for short-term relief of heartburn in patients with persistent symptoms who are treated empirically for GERD and in those in whom esophagitis was excluded after endoscopy. The benefit of PPIs compared with $\mathrm{H}_{2}$ RAs is more pronounced in patients treated empirically.

Received from the Julius Center for Health Sciences and Primary Care, University Medical Center Utrecht (BvP, MEN, NJdW), Utrecht, The Netherlands; Tufts University, New England Medical Center (BvP, JL, PALB), Boston, Mass; and Durham University (APSH), Durham, England, United Kingdom.

Address correspondence and requests for reprints to Dr. Numans: Julius Centre for Health Sciences and Primary Care, University Medical Center Utrecht, PO Box 85060, 3508 AB Utrecht, The Netherlands (e-mail: m.e.numans@med.uu.nl).
KEY WORDS: GERD; treatment; PPI; systematic review; primary care.

J GEN INTERN MED 2003;18:755-763.

G astroesophageal reflux disease (GERD) has been defined as chronic symptoms or mucosal damage produced by the abnormal reflux of gastric contents into the esophagus. ${ }^{1}$ The cardinal manifestation of GERD, heartburn, is experienced monthly by approximately $25 \%$ of adults in developed countries, while at least $5 \%$ have it daily. ${ }^{2-6}$ Such patients experience a decreased quality of life. ${ }^{7}$

A number of treatments for GERD have proven to be effective in controlled clinical trials. Most studies focused on patients who had relatively advanced clinical features of the disease, such as endoscopic evidence of esophageal mucosal injury (i.e., esophagitis). In such patients, treatment with proton pump inhibitors (PPIs) is more effective for healing esophagitis and improving symptoms than are other forms of medical therapy. ${ }^{8}$

The applicability of the results of these studies to daily practice is unclear. In contrast with the patients studied in most of the controlled clinical trials (who were included after diagnostic endoscopy), the majority of patients in primary care are treated empirically. Endoscopy is usually reserved for those with refractory symptoms or alarm symptoms such as dysphagia or bleeding. ${ }^{1,9}$ The efficacy of various pharmacological management options for patients who are treated empirically, based on symptoms only, is probably less predictable than for those in whom GERD has been documented by specific testing, such as with endoscopy or 24-hour pH studies.

Furthermore, approximately one half to two thirds of patients with symptoms suggestive of GERD have no signs of esophagitis on endoscopy. ${ }^{10-14}$ The goal of treatment in these patients is relief of symptoms and thus improvement in quality of life. Whether proton pump inhibitors have a significant advantage compared to histamine-2 receptor antagonists $\left(\mathrm{H}_{2} \mathrm{RAs}\right)$ in achieving these objectives in patients without esophagitis has not been well established.

Patients with symptoms suggestive of GERD but with normal endoscopic findings have been referred to as having 
endoscopy-negative reflux disease (ENRD). ${ }^{11,15}$ Although some of these patients have pathologic acid reflux on 24-hour pH studies, others appear to have exaggerated sensitivity to normal esophageal acid exposure, possibly responsive to antisecretory therapy as well. ${ }^{16,17}$

The purpose of this study was to assess and summarize the efficacy of acid-reducing drug treatment in achieving complete symptom relief for GERD in patients either treated empirically (without a preceding endoscopy), or who had normal results in endoscopy.

\section{METHODS}

\section{Searching}

The electronic databases MEDLINE (1966 to July 2002), EMBASE (1978 to 2000) and the Cochrane Controlled Trials Register were searched using the text words and subject headings heartburn, gastro-(o)esophageal reflux, GERD (GORD), (o)esophagitis, dyspepsia, randomized controlled trial, controlled clinical trial, single-blind method, doubleblind method, random allocation, esomeprazole, lansoprazole, omeprazole, pantoprazole, rabeprazole, cimetidine, famotidine, nizatidine, and ranitidine. Titles and abstracts of English and non-English articles were screened for eligibility. The full text of selected trials was further reviewed independently by 2 of the authors (BP and MN) to confirm eligibility, assess quality, and extract data using a data extraction form. Bibliographies of all articles were reviewed to retrieve additional studies.

\section{Selection}

Randomized controlled trials comparing the efficacy of short-term treatment ( 1 to 12 weeks) with proton pump inhibitors (i.e., esomeprazole, lansoprazole, omeprazole, pantoprazole or rabeprazole) and $\mathrm{H}_{2}$ RAs (i.e., cimetidine, famotidine, nizatidine, or ranitidine) with placebo or with each other were eligible provided that they included subjects 18 years or older presenting with predominant heartburn or acid regurgitation, and diagnosed as having GERD based upon clinical features. Two groups of patients were considered separately. To evaluate empirical treatment strategies, trials were included if patients with symptoms of GERD were enrolled without undergoing a diagnostic upper endoscopy. Studies that used endoscopy were included also, but only if no distinction was made in allocating treatment based upon the endoscopic findings other than exclusion of patients with peptic ulcer disease or severe esophagitis (i.e., ulcers or confluent erosions). To evaluate treatment of ENRD, studies were eligible that included symptomatic subjects who had no evidence of erosive esophagitis on endoscopy.

Trials were ineligible if they were limited to intragroup comparisons (e.g., cimetidine versus ranitidine) or to comparing different dosages of the same drug (e.g., ranitidine $150 \mathrm{mg}$ bid versus ranitidine $300 \mathrm{mg}$ bid). Trials were also ineligible if they included only subjects with endoscopically proven esophagitis, if they used special testing to include patients (i.e., pH study or Bernstein test), or focused only on specific subgroups of GERD patients (i.e., with gastroparesis, hiatus hernia, scleroderma, or extra-esophageal manifestations).

The outcome of primary interest was unambiguous and/or complete relief of symptoms. This was achieved by including studies that reported outcomes in patients with no more than 1 episode of mild heartburn during the week prior to termination of the trial; this included patients with complete heartburn resolution or complete symptom relief. Studies reporting "symptom improvement" or "sufficient symptom control" without a more objective measure of relief were excluded. Secondary endpoints were change in quality of life and the use of antacids for breakthrough symptoms.

\section{Validity Assessment}

The quality of each study was assessed by recording the methodological features most relevant to the control of bias: randomization and allocation concealment. In accordance with Cochrane Systematic Reviews, allocation concealment was then qualified as adequate, possibly adequate, inadequate, or not described.

\section{Data Abstraction}

Data were extracted by 2 investigators independently (BP, MN) using a data extraction form. Consensus was achieved for all data. For each treatment, arm the following outcome data were extracted: number of patients randomized, number in favor of a specific outcome, and change in symptoms or quality of life.

\section{Study Characteristics}

Details on study design and setting; age, sex, symptoms, and possible endoscopic findings of the subjects; type, dosage, and duration of the interventions; and outcome definitions were recorded.

\section{Quantitative Data Synthesis}

The efficacy of the different proton pump inhibitors and $\mathrm{H}_{2}$ RAs was compared with placebo and between drug classes. Relative risks (RRs) and their 95\% confidence intervals (95\% CIs) were calculated from the extracted data for each study. A difference in efficacy was considered significant when the $95 \%$ CI did not include one. The number needed to treat for benefit was calculated by taking the inverse of the absolute risk difference. All analyses were based on intention to treat (ITT). For the purpose of our formal meta-analysis, a pooled estimate of the relative risks for heartburn relief was calculated if appropriate, using a random effects model, which provides a more conservative estimate of the overall treatment response by incorporating between-study heterogeneity. We performed random effects pooling for each measure by weighting study rates by the 
inverse of their variance plus the among-study variance for that measure. We also performed pooling using a fixedeffects model, which provided similar point estimates. Only the random-effects values (expressed as relative risks) are reported, because they provide wider confidence intervals. ${ }^{18} \mathrm{We}$ chose to express summary estimates as relative risk (as opposed to risk difference or odds ratio), because it has favorable mathematical properties for meta-analysis (particularly when there is heterogeneity of results and/or differences in control rates across studies) and because it is relatively easily interpreted. ${ }^{19-21}$ At low event rates, risk ratio and odds ratio are approximately equal.

For trials with more than 1 PPI arm, only the results of the arm receiving standard dose PPI therapy were included in the meta-analysis. For trials presenting outcome at various endpoints, only the endpoint after the longest interval within the observed time frame (0-12 weeks) was included. Statistical heterogeneity between studies was evaluated by using the $\chi^{2}$ test comparing numbers of patients symptom free and was considered significant for $P$ values <.10. Statistical analysis was performed using Meta-Analyst version 0.991 (Joseph Lau, Boston, Mass) and Review Manager 4.1.1 (The Cochrane Collaboration, Wintertree Software, Inc., Nepean, Ontario) software packages. Change in quality of life was analyzed comparing group means, using the Student $t$ test.

\section{RESULTS}

The search strategy identified 1,408 potentially relevant studies. Only 32 were randomized-controlled trials (RCTs) on empirical treatment of GERD or on treatment of ENRD. Nine ${ }^{22-30}$ of these reported no binary outcomes, and another $3^{31-33}$ reported outcomes not meeting our strict criteria. Seven trials ${ }^{34-40}$ were excluded because they used Bernstein testing or a $\mathrm{pH}$ study to include patients. Thus, 13 RCTs were available for analysis: 7 in the empirical treatment group (Table 1) and 9 in the ENRD group (Table 2). Three RCTs ${ }^{41-43}$ were included in both groups. Most of the other excluded studies either focused on patients with documented esophagitis or were not clinical trials. Only published data were included.

\section{Study Characteristics}

Empirical Treatment for GERD. Seven trials were eligible for the analysis of empirical treatment for GERD. They were all conducted in North America and Europe. All were multicenter trials. In $2,^{43,44}$ patients were recruited exclusively by primary care physicians, in $1^{45}$ from both primary and secondary care centers. The other studies provided no details on patient recruitment. A total number of 3,433 subjects were included. The mean number randomized per trial was 490 (range, 208-994); the mean age was 49 years, and $50 \%$ of the participants were male. One trial included patients with any combination of 2 of the following complaints: heartburn, epigastric pain, and regurgitation. ${ }^{46}$ In all other trials, the primary inclusion criterion was heartburn meeting certain criteria defining severity, frequency, and duration. In 1 study, no endoscopy was performed. ${ }^{44}$ In all other studies, patients with severe esophagitis were excluded from randomization. Other exclusion criteria were similar among the studies. They included Barrett's esophagus, esophageal stricture, peptic ulcer disease, and the recent use of antisecretory drugs.

Treatment for ENRD. Nine trials were eligible for analysis of treatment for ENRD. They were conducted in Europe, Australia, and North America. All were multicenter trials. In only $2,{ }^{43,47}$ patients were recruited exclusively by primary care physicians. The other studies provided no details on patient recruitment.

Data were extracted from 2,520 participants with a mean age of 49 years; 46 percent of the participants were male. The mean number of patients randomized per trial in this group was 280 (range, 78-677). One trial ${ }^{48}$ included patients with heartburn and regurgitation. Heartburn alone, meeting different criteria, was the primary inclusion criterion in all other trials. Patients with any degree of erosive esophagitis were excluded from all studies in this group. Other common exclusion criteria were similar to those in the empirical treatment group.

\section{Quantitative Data Synthesis}

Empirical Treatment for GERD. Allocation concealment in 3 trials $^{42,43,46}$ was qualified as possibly adequate. In all other trials, allocation concealment was qualified as adequate. All studies were analyzed on an ITT basis.

The relative risk for heartburn relief in the only placebo-controlled empirical treatment PPI trial (omeprazole standard dose) was 0.35 (95\% CI, 0.26 to $0.46 ; 320$ subjects; Table 3 ). In the 2 placebo-controlled $\mathrm{H}_{2} \mathrm{RA}$ trials, the ranitidine standard dose was significantly superior to placebo; when the results were pooled, the RR was 0.77 (95\% CI, 0.60 to $0.99 ; 1,013$ subjects). In all 4 studies making a direct comparison, PPIs (both standard and half dose) were significantly more effective than $\mathrm{H}_{2}$ RAs (standard and double dose). When the results on standard dose PPI were pooled, the RR was 0.55 (95\% CI, 0.44 to 0.68 ; 1,535 subjects). Low dose PPIs also appeared to be somewhat more effective than $\mathrm{H}_{2}$ RAs in empirical treatment of GERD (RR 0.83; 95\% CI, 0.75 to 0.92).

Statistically significant heterogeneity was detected in the trials comparing different drug classes ( $\chi^{2}$ test: $P=.02$ ). This could partially be explained by a combination of shorter treatment duration and a firmer outcome assessment-both possibly decreasing efficacy - in 1 of the studies. ${ }^{45}$ Heterogeneity also was found among the $\mathrm{H}_{2} \mathrm{RA}$ versus placebo trials ( $\chi^{2}$ test: $P=.04$ ). It could be explained by a difference in treatment duration (2 vs 6 weeks) between the studies. Sensitivity analysis did not reveal significant changes in pooled relative risks, and no differences in direction of results were detected. 


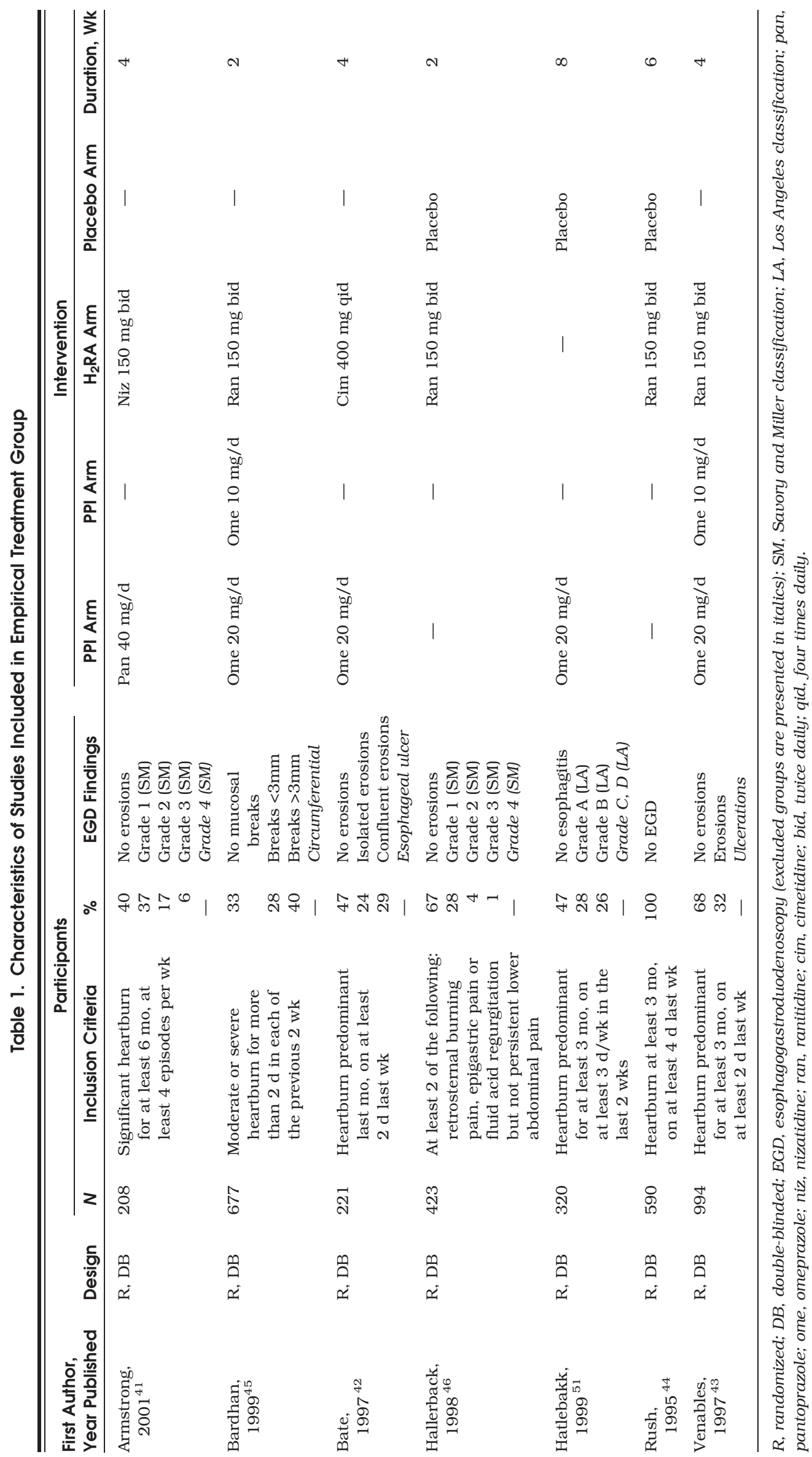


Treatment for ENRD. Allocation concealment in 2 trials was qualified as adequate. ${ }^{41,49}$ In all other trials, allocation concealment was qualified as possibly adequate. Data from all studies could be analyzed on an ITT basis.

The relative risks for heartburn relief in studies comparing a PPI (standard and half dose) to placebo in ENRD were in favor of the active drug in 7 out of 9 comparisons or in 4 out of 5 studies (Table 3). Pooling of data from the 5 studies, with a total of 1,070 subjects, showed a RR of 0.64 (95\% CI, 0.52 to 0.79). Cimetidine standard dose was significantly superior to placebo (RR, 0.78 ) in the only placebo-controlled $\mathrm{H}_{2} \mathrm{RA}$-trial (125 subjects). In a direct comparison between PPI and $\mathrm{H}_{2} \mathrm{RA}$ in ENRD, 1 out of 4 comparisons showed a significant superiority for the PPI; when the results on standard dose PPI were pooled (622 subjects), the RR was 0.81 (95\% CI, 0.70 to 0.95 ). Only 1 study directly compared low dose PPI with $\mathrm{H}_{2} \mathrm{RA}$ in ENRD, and this study showed no significant difference in treatment effect (RR, 0.90; 95\% CI, 0.75 to 1.07). ${ }^{43}$
Statistical heterogeneity was detected among the placebo-controlled PPI trials ( $\chi^{2}$ test, $\left.P<.01\right)$. This could partially be explained by a stricter outcome measure in 1 of the studies. ${ }^{47}$ Sensitivity analysis did not reveal significant changes in pooled relative risks, and no differences in direction of results were detected.

Secondary Endpoints. Validated quality-of-life instruments were used to assess clinical outcome in 3 trials, ${ }^{44,47,50}$ while 1 of the studies presented the results in 2 separate publications. ${ }^{49,50}$ Two ${ }^{47,50}$ studies used the Gastrointestinal Symptom Rating Scale (GSRS), while $1^{50}$ used the Psychological General Well-being (PGWB) index. One trial used a variation (the acute form) of the Short-form Health Survey (SF-36) as well as a heartburn-specific questionnaire. ${ }^{44}$ In the 2 studies on ENRD reporting quality-of-life measures, therapy with omeprazole $(20 \mathrm{mg}$ and $10 \mathrm{mg}$ once daily) compared with placebo was associated with significant improvement in the PGWB index ${ }^{50}$ and the GSRS reflux dimension, ${ }^{47,50}$ but not the

Table 2. Characteristics of Studies Included in Endoscopy-negative Group

\begin{tabular}{|c|c|c|c|c|c|c|c|c|}
\hline $\begin{array}{l}\text { First Author, } \\
\text { Year Published }\end{array}$ & Design & \multicolumn{2}{|r|}{ Participants } & \multicolumn{5}{|c|}{ Intervention } \\
\hline $\begin{array}{l}\text { Bate, } \\
\quad 1996^{52}\end{array}$ & $\mathrm{R}, \mathrm{DB}$ & 209 & $\begin{array}{l}\text { Heartburn predominant, } \\
\text { overall symptoms } \\
\text { moderate }\end{array}$ & Ome $20 \mathrm{mg} / \mathrm{d}$ & - & - & Placebo & 4 \\
\hline $\begin{array}{l}\text { Bate, } \\
1997^{42}\end{array}$ & $\mathrm{R}, \mathrm{DB}$ & 103 & $\begin{array}{l}\text { Heartburn predominant } \\
\text { last mo, on at least } \\
2 \mathrm{~d} \text { last wk }\end{array}$ & Ome $20 \mathrm{mg} / \mathrm{d}$ & - & Cim 400 mg qid & - & 4 \\
\hline $\begin{array}{l}\text { Carlsson, } \\
1998^{47}\end{array}$ & $\mathrm{R}, \mathrm{DB}$ & 261 & $\begin{array}{l}\text { Heartburn for at least } \\
3 \text { mo, symptoms on } \\
\text { at least } 2 \text { d last wk }\end{array}$ & Ome $20 \mathrm{mg} / \mathrm{d}$ & Ome $10 \mathrm{mg} / \mathrm{d}$ & - & Placebo & 4 \\
\hline $\begin{array}{l}\text { Miner, } \\
2002^{53}\end{array}$ & $\mathrm{R}, \mathrm{DB}$ & 199 & $\begin{array}{l}\text { Heartburn for at least } \\
3 \text { mo }\end{array}$ & $\mathrm{Rab} 20 \mathrm{mg} / \mathrm{d}$ & $\mathrm{Rab} 10 \mathrm{mg} / \mathrm{d}$ & - & Placebo & 4 \\
\hline $\begin{array}{l}\text { Richter, } \\
2000^{54}\end{array}$ & $\mathrm{R}, \mathrm{DB}$ & 359 & $\begin{array}{l}\text { At least } 1 \mathrm{y} \text { with } \\
\text { heartburn as } \\
\text { predominant symptom } \\
\text { of GERD, and } \\
\text { moderate to severe on } \\
\text { at least } 4 \mathrm{~d} \text { last wk }\end{array}$ & Ome $20 \mathrm{mg} / \mathrm{d}$ & Ome $10 \mathrm{mg} / \mathrm{d}$ & - & Placebo & 4 \\
\hline $\begin{array}{l}\text { Riemann, } \\
1991^{48}\end{array}$ & $\mathrm{R}, \mathrm{DB}$ & 125 & $\begin{array}{l}\text { Heartburn and } \\
\text { regurgitation for at } \\
\text { least } 2 \text { mo, on at least } \\
5 \text { d last wk }\end{array}$ & - & - & Cim 200 mg qid & Placebo & 2 \\
\hline
\end{tabular}

$R$, randomized; $D B$, double-blinded; pan, pantoprazole; ome, omeprazole; rab, rabeprazole; niz, nizatidine; cim, cimetidine; bid, twice daily; qid, four times daily. 


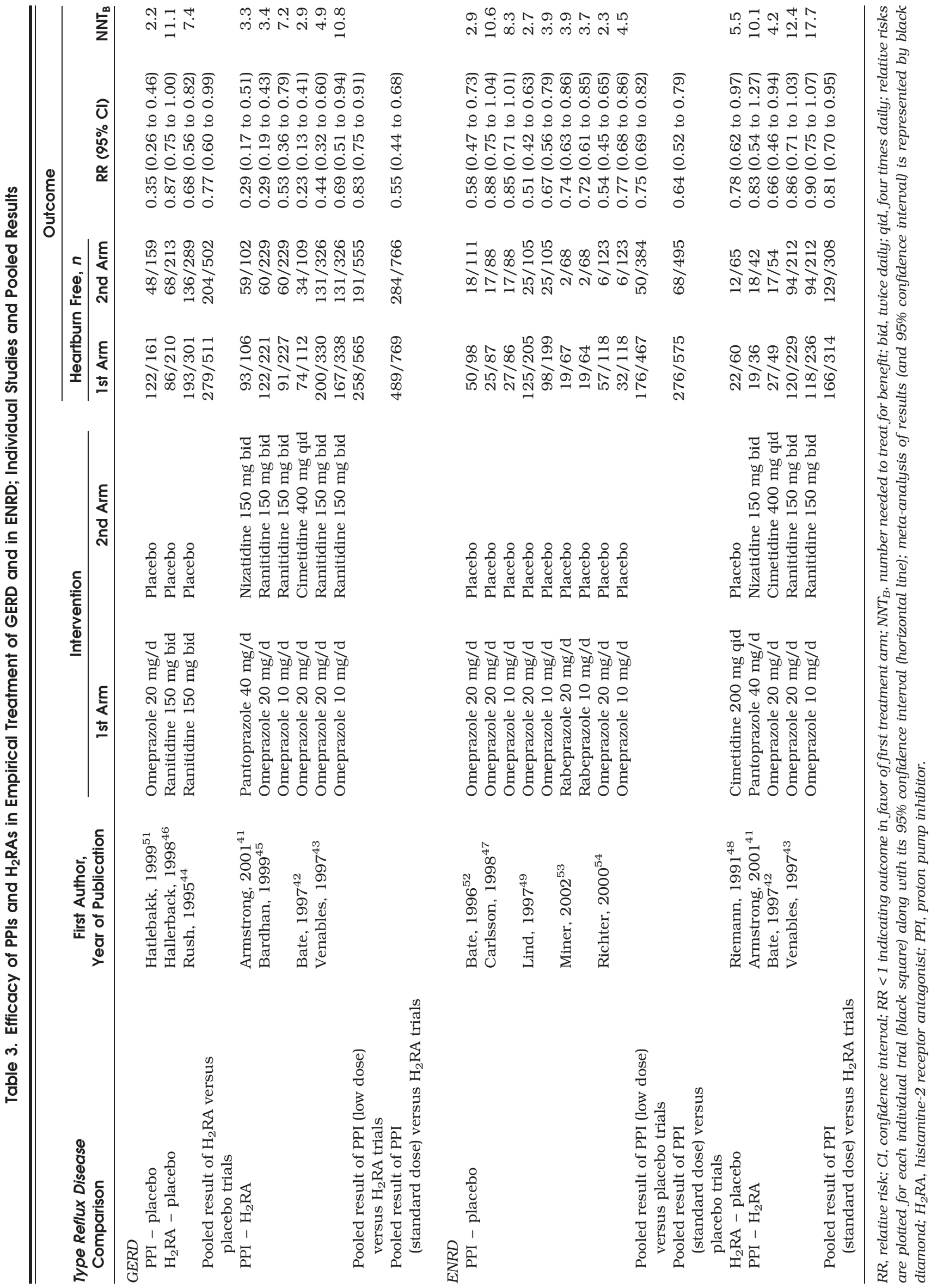


global GSRS score. ${ }^{50}$ One study found significant differences between the effect of ranitidine (150 mg twice daily) and placebo on all scales of the heartburn-specific quality-of-life questionnaire, but only on 3 (physical functioning, bodily pain and vitality) of the SF-36. ${ }^{44}$

All but $1^{48}$ trial permitted the use of antacids in patients with breakthrough symptoms. In general, antacids appeared to be used more frequently in the placebo group and in the group randomized to receive the least effective drug, although there were insufficient data to formally test this hypothesis.

\section{DISCUSSION}

The available evidence summarized in this metaanalysis suggests that a short course with any of the antisecretory drug classes investigated is effective in controlling symptoms in patients with GERD treated empirically, and in patients who have symptoms of GERD but no abnormal findings on endoscopy. Only 1 placebo-controlled PPI trial ${ }^{51}$ on short-term empirical treatment for GERD was identified, probably reflecting the ethical considerations of using placebo in symptomatic patients. In empirical treatment of GERD, PPIs (standard or half dose) were superior to $\mathrm{H}_{2} \mathrm{RAs}$ (standard dose) in all trials in which they were compared. In ENRD, standard dose PPIs were more effective than $\mathrm{H}_{2}$ RAs; there were insufficient data to make any conclusions regarding low dose PPIs in patients with ENRD.

The use of antacids as rescue medication was allowed in most of the trials in this study. In general, patients randomized to less-effective therapy used more antacids. It is possible that this trend reduced the estimate of the treatment benefit in patients receiving the more-effective therapy. Interestingly, it also may contribute to the high healing rates that have been observed in placebo groups in clinical trials of patients with esophagitis. ${ }^{8}$

It can be argued that our empirical group was not truly empirical, since endoscopy was performed in all but 1 trial and some patients were excluded because of either severe or complicated esophagitis or peptic ulcer disease. Most of the studies did not report the number of patients excluded based upon endoscopic findings. In 1 of the studies that $\operatorname{did},{ }^{46}$ only 14 out of 441 patients (3\%) were excluded on the basis of these endoscopic findings. Thus, we believe that the empirical group represented a good reflection of the adult population presenting with a history of serious and relatively long-standing but uncomplicated GERD.

Only studies with binary data on complete or nearcomplete symptom relief, a relatively strict definition of treatment success, were included in our formal metaanalysis. Although this reduced the number of eligible studies, it also selected for studies that used relatively uniform outcome definitions, making it easier to translate the results to daily practice. However, a more standardized outcome measure for assessment of symptom relief would be desirable for future studies. Similarly, only a few studies reported changes in validated quality-of-life instruments, and the majority of the quality-of-life instruments used in these studies were not specifically designed for patients with GERD. This important component of clinical efficacy should be incorporated more consistently into future trials.

The chronic relapsing nature of GERD usually requires long-term maintenance treatment. Our study focused only on short-term treatment trials, and thus results cannot be extrapolated into maintenance therapy. Relatively few studies were available for analysis considering that the population that we focused on represents the majority of patients seeking care for symptoms of GERD. More studies are needed comparing different classes of medications.

In conclusion, the available evidence suggests that short-term treatment with antisecretory drugs is effective for patients with typical symptoms of GERD who are treated empirically and for those with typical symptoms who did not have endoscopic signs of esophagitis. Superiority of PPIs (standard dose) to $\mathrm{H}_{2} \mathrm{RAs}$ was demonstrated in patients treated empirically (RR, 0.55; 95\% CI, 0.44 to 0.68), as well as in the treatment of those without esophagitis on endoscopy (ENRD; RR, 0.81; 95\% CI, 0.70 to 0.95). Standard dose PPIs were slightly less superior to $\mathrm{H}_{2} \mathrm{RAs}$ in the ENRD compared with the empirical group. One possible explanation may be that the empirical group had a higher proportion of patients with esophagitis; such patients generally respond better to PPIs than to $\mathrm{H}_{2}$ RAs. Thus, the choice of drug classes in early empirical treatment of GERD might ideally depend on an estimate of the likelihood of esophagitis, since in those without esophagitis, PPI therapy may not always be necessary. To improve the possibilities of translating these results into strategies for pragmatic care, more needs to be learned about identifying patients with "typical" GERD symptoms and about estimating the proportion of those with mucosal damage due to GERD. In addition, most of the patients in this meta-analysis had symptoms for only a moderate length of time, while "true" GERD is considered to be a chronic disease. Thus, the conclusion that standard dose PPI therapy is superior to $\mathrm{H}_{2}$ RAs for the initial short-term treatment of GERD can only be drawn for primary care patients or outpatients in general internal clinics presenting with relatively serious and/or recurring heartburn. Patients with less-typical symptoms or only having symptoms for a short time might benefit equally from $\mathrm{H}_{2} \mathrm{RA}$ or PPI therapy.

This research is part of the GERD-guidelines project that was initiated by the European Society for Primary Care Gastroenterology, was conducted in cooperation with the Upper Gastrointestinal and Pancreatic Diseases Group of the Cochrane Collaboration, and also was supported by a grant of the Agency for Healthcare Research and Quality of the U.S. Public Health Service, R25 HSO9796.

\section{REFERENCES}

1. DeVault KR, Castell DO. Updated guidelines for the diagnosis and treatment of gastroesophageal reflux disease. Am J Gastroenterol. 1999;94:1434-42. 
2. Corder AP, Jones RH, Sadler GH, Daniels P, Johnson CD. Heartburn, oesophagitis and Barrett's oesophagus in self-medicating patients in general practice. Br J Clin Pract. 1996;50:245-8.

3. Isolauri J, Laippala P. Prevalence of symptoms suggestive of gastro-oesophageal reflux disease in an adult population. Ann Med. 1995;27:67-70.

4. Locke GR, Talley NJ, Fett SL, Zinsmeister AR, Melton LJ. Prevalence and clinical spectrum of gastroesophageal reflux: a population-based study in Olmsted County, Minnesota. Gastroenterology. 1997;112:1448-56.

5. Nebel OT, Fornes MF, Castell DO. Symptomatic gastroesophageal reflux: incidence and precipitating factors. Am J Dig Dis. 1976;21: 953-6.

6. Thompson WG, Heaton KW. Heartburn and globus in apparently healthy people. Can Med Assoc J. 1982;126:46-8.

7. Dimenas E, Carlsson G, Glise H, Israelsson B, Wiklund I. Relevance of norm values as part of the documentation of quality of life instruments for use in upper gastrointestinal disease. Scand J Gastroenterol. 1996;221(suppl):8-13.

8. Chiba N, De Gara CJ, Wilkinson JM, Hunt RH. Speed of healing and symptom relief in grade II to IV gastroesophageal reflux disease: a meta-analysis. Gastroenterology. 1997;112:1798-810.

9. Kroes RM, Numans ME, Jones RH, de Wit NJ, Verheij TJM. Gastrooesophageal reflux disease in primary care. Comparison and evaluation of existing national guidelines and development of uniform European guidelines. Eur J Gen Pract. 1999;5:88-97.

10. Joelsson B, Johnsson F. Heartburn - the acid test. Gut. 1989;30: 1523-5.

11. Johansson KE, Ask P, Boeryd B, Fransson SG, Tibbling L. Oesophagitis, signs of reflux, and gastric acid secretion in patients with symptoms of gastro-oesophageal reflux disease. Scand J Gastroenterol. 1986;21:837-47.

12. Johnsson F, Joelsson B, Gudmundsson K, Greiff L. Symptoms and endoscopic findings in the diagnosis of gastroesophageal reflux disease. Scand J Gastroenterol. 1987;22:714-8.

13. Robinson M, Earnest D, Rodriguez-Stanley S, et al. Heartburn requiring frequent antacid use may indicate significant illness. Arch Intern Med. 1998;158:2373-6.

14. Tefera L, Fein M, Ritter MP, et al. Can the combination of symptoms and endoscopy confirm the presence of gastroesophageal reflux disease? Am Surg. 1997;63:933-6.

15. Dent J. Gastro-oesophageal reflux disease. Digestion. 1998;59: 433-45.

16. Rodriguez-Stanley S, Robinson M, Earnest DL, Greenwood-Van MB, Miner PB Jr. Esophageal hypersensitivity may be a major cause of heartburn. Am J Gastroenterol. 1999;94:628-31.

17. Shi G, Bruley des Varannes S, Scarpignato C, Le Rhun M, Galmiche JP. Reflux related symptoms in patients with normal oesophageal exposure to acid. Gut. 1995;37:457-64.

18. Laird NM, Mosteller F. Some statistical methods for combining experimental results. Int $\mathrm{J}$ Technol Assess Health Care. 2003;24: 243-6.

19. Lau J, Ioannidis JPA, Schmid CH. Summing up evidence: one answer is not always enough. Lancet. 1998;351:123-7.

20. Engels EA, Schmid CH, Terrin N, Olkin I, Lau J. Heterogeneity and statistical signficance in meta-analysis: an empirical study of 125 meta-analyses. Stat Med. 2000;19:1707-28.

21. Deeks JJ. Issues in the selection of summary statistics of metaanalyses of clinical trials with binary outcomes. Stat Med. 2002;21: 1575-600.

22. Schindlbeck NE, Klauser AG, Voderholzer WA, Muller-Lissner S. Empiric therapy for gastroesophageal reflux disease. Arch Intern Med. 1995;155:1808-12.

23. Robinson MG, Orr WC, McCallum R, Nardi R. Do endoscopic findings influence response to $\mathrm{H}_{2}$ antagonist therapy for gastroesophageal reflux disease? Am J Gastroenterol. 1987;82:519-22.

24. Powell-Jackson P, Barkley H, Northfield TC. Effect of cimetidine in symptomatic gastro-oesophageal reflux. Lancet. 1978;2:1068-9.
25. Marrero JM, de Caestecker JS, Maxwell JD. Effect of famotidine on oesophageal sensitivity in gastro-oesopahgeal reflux disease. Gut. 1994;35:447-50.

26. Johnsson F, Weywadt L, Solhaug J-H, Hernqvist H, Bengtsson L. One-week omeprazole treatment in the diagnosis of gastrooesophageal reflux disease. Scand J Gastroenterol. 1998;33: 15-20.

27. Johnsson F, Roth Y, Damgaard Pedersen N-E, Joelsson B. Cimetidine improves GERD symptoms in patients selected by a validated GERD questionnaire. Aliment Pharmacol Ther. 1993;7:81-6.

28. Jebbink HJA, Smout AJPM, van Berge Henegouwen GP. Ranitidine vooral werkzaam bij functionele dyspepsie met klachten passend bij refluxziekten. Ned Tijdschr Geneeskd. 1993;137:1772-5.

29. Greaney MG, Irvin TT. Cimetidine for the treatment of symptomatic gastro-oesophageal reflux. Br J Clin Pract. 1981;35:21-4.

30. Bennett JR, Buckton G, Martin HD. Cimetidine in gastrooesophageal reflux. Digestion. 1983;26:166-72.

31. Johansson KE, Boeryd B, Johansson K, Tibbling L. Double-blind crossover study of ranitidine and placebo in gastro-oesophageal reflux disease. Scand J Gastroenterol. 1986;21:769-78.

32. Richter JE, Campbell DR, Kahrilas PJ, Huang B, Fludas C. Lansoprazole compared with ranitidine for the treatment of nonerosive gastroesophageal reflux disease. Arch Intern Med. 2000; 160:1803-9.

33. Schenk BE, Kuipers EJ, Klinkenberg-Knol EC, et al. Omeprazole as a diagnostic tool in gastroesophageal reflux disease. Am J Gastroenterol. 1997;92:1997-2000 (see comments).

34. Behar J, Brand DL, Brown FC, et al. Cimetidine in the treatment of symptomatic gastroesophageal reflux: a double blind controlled trial. Gastroenterology. 1978;74:441-8.

35. Bright-Asare P, El-Bassoussi M. Cimetidine, metoclopramide, or placebo in the treatment of symptomatic gastroesophageal reflux. J Clin Gastroenterol. 1980;2:149-56.

36. Fiasse R, Hanin C, Lepot A, Descamps C, Lamy F, Dive C. Controlled trial of cimetidine in reflux esophagitis. Dig Dis Sci. 1980;25:750-5.

37. Robinson M, Decktor DL, Stone RC, et al. Famotidine (20 mg) b.i.d relieves gastrooesophageal reflux symptoms in patients without erosive oesophagitis. Famotidine/GERD Investigation Group. Aliment Pharmacol Ther. 1991;5:631-43.

38. Sabesin SM, Berlin RG, Humphries TJ, Bradstreet DC, WaltonBowen KL, Zaidi S. Famotidine relieves symptoms of gastroesophageal reflux disease and heals erosions and ulcerations. Results of a multicenter, placebo-controlled, dose-ranging study. USA Merck Gastroesophageal Reflux Disease Study Group. Arch Intern Med. 1991;151:2394-400.

39. Sontag S, Robinson M, McCallum RW, Barwick KW, Nardi R. Ranitidine therapy for gastroesophageal reflux disease. Results of a large double-blind trial. Arch Intern Med. 1987;147:1485-91.

40. Watson RG, Tham TC, Johnston BT, McDougall NI. Double blind cross-over placebo controlled study of omeprazole in the treatment of patients with reflux symptoms and physiological levels of acid reflux — the "sensitive oesophagus. Gut. 1997;40:587-90.

41. Armstrong D, Pare P, Pericak D, Pyzyk M, Canadian Pantoprazole GERD Study Group. Symptom relief in gastroesophageal reflux disease: a randomized, controlled comparison of pantoprazole and nizatidine in a mixed patient population with erosive esophagitis or endoscopy-negative reflux disease. Am J Gastroenterol. 2001;96: 2849-57.

42. Bate CM, Green JR, Axon AT, et al. Omeprazole is more effective than cimetidine for the relief of all grades of gastro-oesophageal reflux disease-associated heartburn, irrespective of the presence or absence of endoscopic oesophagitis. Aliment Pharmacol Ther. 1997;11:755-63.

43. Venables TL, Newland RD, Patel AC, Hole J, Wilcock C, Turbitt ML. Omeprazole 10 milligrams once daily, omeprazole 20 milligrams once daily, or ranitidine 150 milligrams twice daily, evaluated as initial therapy for the relief of symptoms of gastro-oesophageal 
reflux disease in general practice. Scand J Gastroenterol. 1997;32: 965-73.

44. Rush DR, Stelmach WJ, Young TL, et al. Clinical effectiveness and quality of life with ranitidine vs placebo in gastroesophageal reflux disease patients: a clinical experience network (CEN) study. J Fam Pract. 1995;41:126-36 (see comments).

45. Bardhan KD, Muller-Lissner S, Bigard MA, et al. Symptomatic gastro-oesophageal reflux disease: double blind controlled study of intermittent treatment with omeprazole or ranitidine. The European Study Group. BMJ. 1999;318:502-7.

46. Hallerback B, Glise H, Johansson B, et al. Gastro-oesophageal reflux symptoms - clinical findings and effect of ranitidine treatment. Eur J Surg. 1998;583:6-13.

47. Carlsson R, Dent J, Watts R, et al. Gastro-oesophageal reflux disease in primary care: an international study of different treatment strategies with omeprazole. International GORD Study Group. Eur J Gastroenterol Hepatol. 1998;10:119-24.

48. Riemann JF, Hobel W. Cimetidine suspension in patients with stage 0 gastro-oesophageal reflux disease. Aliment Pharmacol Ther. 1991;5:191-7.
49. Lind $\mathrm{T}$, Havelund $\mathrm{T}$, Carlsson $\mathrm{R}$, et al. Heartburn without oesophagitis: efficacy of omeprazole therapy and features determining therapeutic response. Scand J Gastroenterol. 1997;32: 974-9.

50. Havelund T, Lind T, Wiklund I, et al. Quality of life in patients with heartburn but without esophagitis: effects of treatment with omeprazole. Am J Gastroenterol. 1999;94:1782-9.

51. Hatlebakk JG, Hyggen A, Madsen PH, et al. Heartburn treatment in primary care: randomised, double blind study for 8 weeks. BMJ. 1999;319:550-3.

52. Bate CM, Griffin SM, Keeling PW, et al. Reflux symptom relief with omeprazole in patients without unequivocal oesophagitis. Aliment Pharmacol Ther. 1996;10:547-55.

53. Miner PB Jr, Orr W, Filippone J, Jokubaitis L, Sloan S. Rabeprazole in nonerosive gastroesophageal reflux disease: a randomized placebo-controlled trial. Am J Gastroenterol. 2002; 97:1332-9.

54. Richter JE, Peura D, Benjamin SB, Joelsson B, Whipple J. Efficacy of omeprazole for the treatment of symptomatic acid reflux disease without esophagitis. Arch Intern Med. 2000;160:1810-6. 